\title{
Correction to: Migration and Families in European Society
}

\author{
Laura Zanfrini
}

\section{Correction to:}

Chapter 23 in: A.-M. Castrén et al. (eds.), The Palgrave Handbook of Family Sociology in Europe, https://doi.org/10.1007/978-3-030-73306-3_23

The original version of this chapter was inadvertently published with an incorrect affiliation of the author Laura Zanfrini in Chapter 23, which has now been updated from "Universita Cattolica, Milan, Italy" to "Fondazione ISMU, Milan, Italy". The chapter has been updated with the changes. 